\title{
Chute Certo: Um Jogo Digital Educativo para Auxiliar no Processo de Alfabetização
}

\author{
Samanta F. Aires ${ }^{1}$, Ynessa B. D. F. Santos ${ }^{1}$, Maria Aparecida A. de Andrade ${ }^{1}$, \\ Lucineide Araújo ${ }^{1}$, Charles Madeira ${ }^{1}$ \\ ${ }^{1}$ Instituto Metrópole Digital - Universidade Federal do Rio Grande do Norte (UFRN) \\ Caixa Postal 1524 - 59078-970 - Natal - RN - Brasil \\ \{samantafaires, ynessafarias, andrade.aparecida15, \\ neidinha.araujo.cruz\}@gmail.com, charles@imd.ufrn.br
}

Abstract. This article presents the digital educational game Chute Certo, wich aims to assist in the literacy process of childrens between 5 and 8 years old. A prototype of the game was developed and validated with students in a public school, presenting positive results in the training of reading skills expected for the level. The game is designed specifically for children's literacy and differs from other similar studies, because it incorporates the user into a soccer game atmosphere, wich culturally arouses interest in brazilian children, and presents the content of reading training through syllable formation and association of words with figures.

Resumo. Este artigo apresenta o jogo digital educativo Chute Certo que tem por objetivo auxiliar no processo da alfabetização de crianças entre 5 e 8 anos. Um protótipo do jogo foi desenvolvido e validado com alunos em uma escola da rede pública de ensino, apresentando resultados positivos na garantia do treino das habilidades de leitura esperadas para o nível. O jogo se insere no grupo de jogos digitais planejados especificamente para alfabetização de crianças e difere-se de outros trabalhos similares por incorporar o usuário em uma atmosfera de jogo de futebol, que culturalmente desperta o interesse nas crianças brasileiras, e apresenta o conteúdo de treinamento da leitura através da formação de sílabas e da associação de verbetes com figuras apresentadas.

\section{Introdução}

A garantia da alfabetização na idade certa é a meta 5 do Plano Nacional da Educação (PNE), e está entre os muitos desafios enfrentados na educação básica nacional, principalmente dentro dos cenários das escolas públicas do país - que são precárias em suas estruturas física e humanas, o que distancia os profissionais da educação de resultados de qualidade em seu trabalho.

O Pacto Nacional pela Alfabetização na Idade Certa (PNAIC) desenvolve ações com o objetivo de atender à Meta 5 do PNE - que estabelece a obrigatoriedade de se alfabetizar todas as crianças até o final do $3^{\circ}$ ano do ensino fundamental. No entanto, a realidade que observamos é que parte considerável dos estudantes passa do $3^{\circ}$ ano com níveis de proficiência insuficientes para a sua idade/série. 
VIII Congresso Brasileiro de Informática na Educação (CBIE 2019)

Anais do XXV Workshop de Informática na Escola (WIE 2019)

Como resultado, vemos índices ainda muito baixos em relação às habilidades de leitura e escrita, a exemplo dos apresentados nos dados divulgados em 2017 sobre a Avaliação Nacional da Alfabetização [ANA 2016] - instrumento utilizado pelo Sistema de Avaliação da Educação Básica (Saeb), que avalia os níveis de leitura e escrita em Língua Portuguesa, a alfabetização em Matemática e as condições de oferta do Ciclo de Alfabetização das redes públicas.

Os resultados da edição de 2016 da ANA sobre a avaliação da leitura revelaram que, em uma escala de 1 à 4, em que 1 é Elementar, 2 é Básico, 3 é Adequado e 4 é Desejável, mais da metade dos estudantes (54,7\%) estão nos níveis 1 e 2, sendo que apenas 45,2\% alcançaram níveis satisfatórios em leitura, com desempenho nos níveis 3 e 4. Ao compararmos esses dados com os da edição de 2014, em que o percentual nos níveis 3 e 4 era de 43,8\%, percebemos que a maioria dos estudantes ainda permanece nos níveis indesejáveis de leitura. Em relação à avaliação da escrita, em 2016, temos que $66,15 \%$ dos estudantes alcançaram os níveis 3 e 4 . O percentual dessa habilidade na edição de 2014 foi de 56,1\%.

A análise desses dados permite-nos refletir que são poucas as mudanças alcançadas, em números, entre os dois anos analisados, mostrando que há uma estagnação no progresso da alfabetização e letramento no país.

Diante desse cenário, entendemos que há muitas carências a serem supridas envolvendo a aquisição das habilidades de alfabetização e letramento. Percebemos também que, quanto mais recursos disponíveis para os profissionais da educação, mais próximos estaremos da meta de alfabetização na idade certa.

Lemle [2006 apud Leão 2015] propõe sugestões para sanar as dificuldades em cada fase de alfabetização, ressaltando também a importância desse conhecimento por parte do professor, para que cobre conhecimentos compatíveis com a fase de alfabetização do aluno, utilizando recursos variados, como o uso de jogos digitais.

$\mathrm{O}$ uso de jogos digitais no contexto escolar têm um papel fundamental, pois podem despertar nas crianças a motivação, a expressividade, a imaginação, a linguagem comunicativa, a atenção, a concentração, o raciocínio lógico, e podem englobar diferentes áreas do conhecimento, sendo um recurso de ponta no processo de alfabetização/letramento [Leão 2015].

$\mathrm{O}$ ato de jogar exige uma movimentação mental e, em muitos momentos, a criança tem que colocar em prática o aprendizado adquirido para avançar pelas fases, testando hipóteses, explorando sua espontaneidade e criatividade. Ao mesmo tempo em que conseguem desenvolver a concentração, o raciocínio lógico e a colaboração entre as crianças, incentivam a leitura e a escrita.

Desafiado por esse cenário, este artigo apresenta o jogo digital educativo Chute Certo, desenvolvido para auxiliar na prática da leitura e formação de palavras, com o intuito de garantir que, de forma lúdica, os jogadores se envolvam no treino das habilidades necessárias para consolidar a proficiência na leitura e escrita. 
VIII Congresso Brasileiro de Informática na Educação (CBIE 2019)

Anais do XXV Workshop de Informática na Escola (WIE 2019)

\section{Jogos para alfabetização}

Existem diversos trabalhos já publicados que trazem a análise de jogos abordando a temática da alfabetização e que buscam consolidar a construção de conhecimento para essa etapa do ensino.

Nogueira et al. (2010) propõem o Papa-Letras, um jogo de computador que desafia o jogador a encontrar, dentro de um labirinto, elementos linguísticos correspondentes a uma imagem que mantém-se projetada no centro da tela, e o jogador deve ser capaz de reconhecer as sílabas para capturar aquelas que formam a imagem. $\mathrm{O}$ jogo difere do Chute Certo por, em alguns momentos, exigir mais a habilidade no domínio da coordenação motora fina que dos conhecimentos alfabéticos, visto que durante todo o percurso o usuário deve manter o personagem no centro da trilha.

No jogo Tiroletras [Coscarelli 2013] o jogador deve atirar em letras com o intuito de formar palavras, em que cada letra representa um inimigo e, para destruí-lo, o jogador deve disparar um tiro com a letra correspondente. A diferença na proposta deste jogo é que o usuário mantém o foco em letras de forma isolada, e não na aplicação delas em sílabas e palavras, como na proposta do Chute Certo.

Pinheiro et al. (2018) propõem uma reconfiguração do jogo "Batalha Naval", que contém letras e números em uma plataforma no mar e o jogador deve escolher uma letra e um número nessa plataforma no intuito de encontrar as sílabas escondidas para formar palavras de um poema utilizado no jogo. A proposta assemelha-se à do Chute Certo, visto que o usuário treina a habilidade de leitura a partir da formação de sílabas. Mas difere por não garantir que o jogador treine as habilidades inerentes à alfabetização enquanto joga, já que, a depender de suas escolhas, ele acessará somente bombas e, com isso, não terá a chance de ler enquanto joga ou brinca.

\section{A Construção do Jogo}

O jogo Chute Certo foi desenvolvido para atender as plataformas desktop e mobile e, assim como no desenvolvimento de um software, fizemos uso do processo de desenvolvimento ágil, sendo esse dividido em cinco etapas: Projeto, Implementação, Testes, Aplicação e Validação.

$\mathrm{Na}$ etapa de Projeto foram realizadas diversas reuniões entre a equipe para definir a visão geral do jogo na primeira versão do protótipo. Assim, definimos os principais requisitos a serem implementados, as mecânicas base, controles, gráficos e tipo de jogabilidade.

$\mathrm{Na}$ etapa de Implementação, realizamos o desenvolvimento do jogo em paralelo a seu design, fazendo uso de imagens de livre distribuição e modificando-as para a temática utilizada no jogo: futebol. Nesta etapa também implementamos todas as mecânicas básicas essenciais ao protótipo, que foi desenvolvido utilizando a engine de construção de jogos Unity $3 D$, e a linguagem de programação $C \#$.

$\mathrm{Na}$ etapa de Testes, verificamos se o protótipo desenvolvido estava de acordo com o projetado na primeira etapa, analisando se todas as funcionalidades definidas 
VIII Congresso Brasileiro de Informática na Educação (CBIE 2019)

Anais do XXV Workshop de Informática na Escola (WIE 2019)

foram desenvolvidas, resultando assim em produto mínimo viável para ser aplicado e validado junto aos usuários.

As últimas etapas foram a Aplicação e Validação, em que aplicamos em sala de aula o executável do protótipo do jogo - em plataforma desktop, com alunos de uma escola pública.

Após o teste, aplicamos um questionário para os jogadores responderem, com o intuito de validar a relevância do jogo no processo lúdico de atividades de alfabetização, verificando a sua usabilidade, satisfação dos alunos em jogar e grau de dificuldade entre as fases e aprendizagem. O questionário foi aplicado com auxílio da professora e apresentava questões objetivas, em que emoticons representavam as respostas, de modo a facilitar o entendimento do mesmo pelo aluno. O modelo do questionário pode ser visualizado na Figura 1.

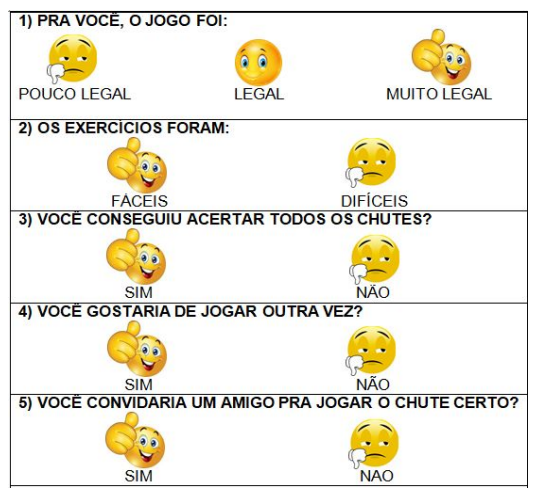

Figura 1. Questionário apresentado aos alunos.

\subsection{O Projeto do Jogo}

A concepção do jogo Chute Certo surgiu em uma disciplina de mestrado e partiu da necessidade, apontada por alguns professores da educação básica, da criação de jogos que auxiliem nas atividades de alfabetização realizadas em sala de aula, com alunos entre 5 e 8 anos.

Dessa forma, na primeira etapa do projeto, estabelecemos como temática do jogo o futebol, por ser um cenário que, culturalmente, desperta bastante interesse nas crianças brasileiras. Também definimos o gameplay, regras, design, sonorização, níveis de dificuldade e as atividades a serem realizadas pelos alunos em cada um desses níveis ao longo do jogo.

\subsection{Elementos Gráficos}

Todas as imagens utilizadas são de disponibilização livre e gratuita na internet e modificadas graficamente para a temática do jogo.

Com interfaces coloridas e seguindo a temática de futebol, o Chute Certo é um jogo baseado na mecânica do point and click (aponte e clique), em que o jogador deverá clicar em um objeto na interface para executar alguma ação.

A primeira tela exibida é o Мenu, apresentado na Figura 2, que apresenta ao jogador diferentes níveis de dificuldade que vão sendo desbloqueados de acordo com 
VIII Congresso Brasileiro de Informática na Educação (CBIE 2019)

Anais do XXV Workshop de Informática na Escola (WIE 2019)

seu progresso no jogo. Neste protótipo inicial são disponibilizados seis níveis de dificuldade, cuja a complexidade dos desafios vai progredindo de forma ascendente de acordo com o nível escolhido.

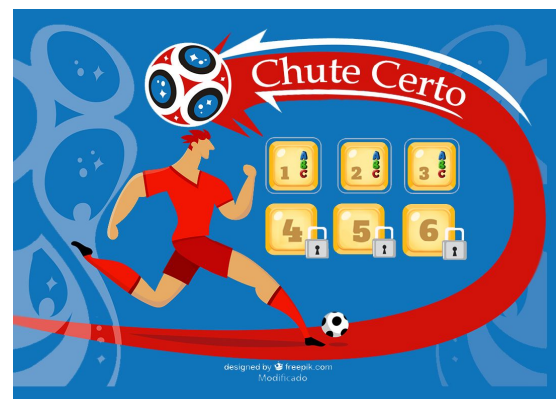

Figura 2. Menu do jogo apresentando os níveis.

Ao clicar no nível desejado, o jogador é transferido para a tela principal do jogo, apresentada na Figura 3.

Os principais elementos gráficos presentes no jogo são as telas dos níveis, que apresentam um plano de fundo representando um campo de futebol, com uma trave ao meio e, no lado direito é apresentado uma imagem de um objeto ou animal com a palavra que a representa, faltando uma sílaba para ser completada.

Também são apresentadas duas bolas de futebol, cada uma exibindo uma sílaba diferente que pode completar a palavra, e que deve ser selecionada corretamente pelo aluno.



Figura 3. Interface com principais elementos gráficos do jogo.

A temática futebol foi escolhida por este ser um cenário familiar para as crianças brasileiras e os alunos se mostraram bastante empolgados em realizar atividades com esse tema.

As imagens selecionadas levam em consideração os níveis de dificuldade na escrita de seus nomes, podendo ser palavras de duas à quatro sílabas simples ou complexas, como palavras compostas de "ch" ou "x", que são consideradas de difícil aprendizado para os alunos. Essa complexidade, como citado anteriormente, vai progredindo de acordo com o nível selecionado.

No nível I são apresentadas palavras dissílabas, com duas letras por sílaba e sem acento. O nível II é composto por palavras trissílabas ou dissílabas com acento ou "ç". E o nível III apresenta palavras com sílabas que geralmente causam dúvida, por possuírem outras possibilidades em sua escrita que gerem o mesmo fonema, como as palavras que 
VIII Congresso Brasileiro de Informática na Educação (CBIE 2019)

Anais do XXV Workshop de Informática na Escola (WIE 2019)

possuem "z" ou "s" e" ch" ou "x" - normalmente de mais difícil compreensão pelos alunos. Podemos ver um exemplo das palavras de cada nível na Figura 4.
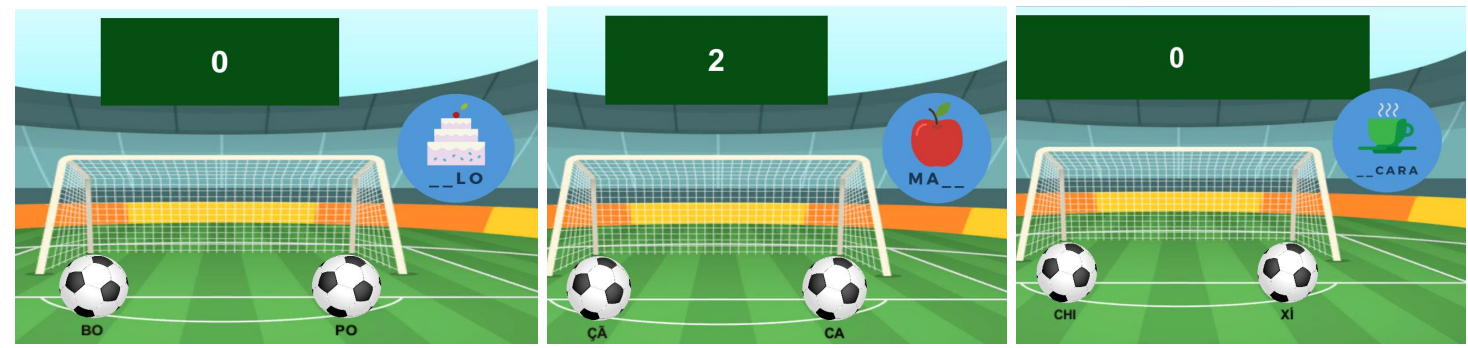

Figura 4. Exemplo de palavras do Nível I, II e III, respectivamente.

\subsection{GamePlay}

Sendo um jogo 2D, a interface é apresentada ao jogador com uma câmera fixa e reta, com a visão um pouco acima da cena, sobre um campo de futebol com foco na área do Gol.

A interface, como já mostrada na Figura 3, apresenta a trave, uma imagem ao seu lado com uma palavra na qual falta uma sílaba. Abaixo do gol são exibidas duas bolas de futebol, uma contendo a sílaba que falta na palavra e a outra contendo uma sílaba aleatória, ou escolhida propositadamente para gerar dúvida. Acima da trave é mostrado o placar, contendo os pontos acumulados pelo jogador de acordo com seus acertos.

O jogador deve clicar em uma das bolas para lançá-la ao gol. Se a bola possuir a sílaba correta, ela é lançada bem no meio do gol e é apresentado um som representando o grito da torcida, junto a uma imagem escrito "Goal".

Ao clicar na bola da sílaba errada, ela é lançada para fora de campo e é mostrada uma imagem com a letra " $X$ " e um som que representa o lamento da torcida. Na Figura 5 apresentamos cada uma das interfaces citadas.
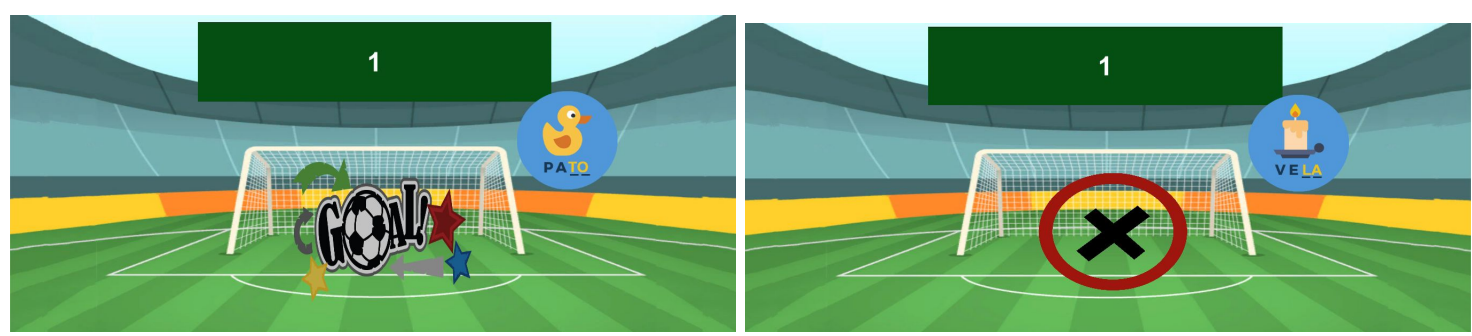

Figura 5. Interface apresentada quando a está resposta correta à esquerda, e quando está incorreta à direita.

A cada bola correta lançada ao gol, é somado um ponto no placar do jogador, e em seguida é apresentada a próxima imagem na fila, junto às suas respectivas sílabas disponíveis para lançamento. Já quando o jogador erra o lançamento de uma bola, não é somado ponto para ele, e também é apresentada a imagem seguinte da fila. 
Ao final do nível selecionado, o jogador é encaminhado para a tela final (Figura 6), na qual são apresentados todos os pontos acumulados por ele naquele nível e é dada a possibilidade de ele retornar ao Menu para selecionar outro nível.

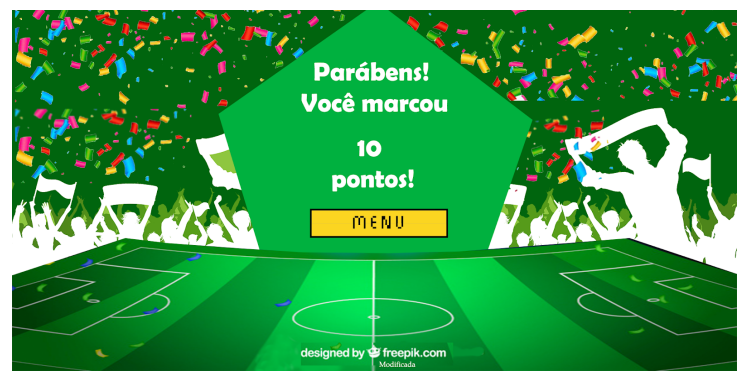

Figura 6. Tela final do jogo, com opção de retorno ao menu.

\section{Aplicação em Sala de Aula}

A etapa de testes foi realizada com estudantes de uma escola da rede pública estadual. Participaram da experiência 24 alunos de uma turma do $2^{\circ}$ ano do Ensino Fundamental I, com idades entre 7 e 8 anos, após as autorizações devidas e apoio das equipes pedagógica e gestora responsáveis.

O momento aconteceu durante o horário da aula, onde que os alunos foram convidados a irem até a sala multimídia da escola para, individualmente, conhecerem e praticarem o jogo na versão desktop utilizando um notebook do setor administrativo da instituição, especialmente cedido para o teste.

Vale salientar que a ocasião foi também a primeira experiência de alguns alunos operando um computador. Logo, com esse grupo especificamente, foi necessária uma explicação básica sobre o manuseio do mouse para, em seguida, dar as orientações referentes ao jogo.

Os participantes entenderam com facilidade a dinâmica do Chute Certo e realizaram as fases oferecidas sem dificuldades, apesar de apenas a minoria do grupo ter acertado todos os exercícios propostos no jogo. Ao final, cada aluno foi orientado a responder um pequeno questionário, com cinco perguntas, para identificarmos como foi a experiência para eles.

De um modo geral, a vivência com o jogo foi muito bem aceita e com feedbacks bastante positivos por parte dos alunos, como mostrado nos gráficos da Figura 7. O jogo foi considerado muito legal por $83,3 \%$ dos usuários e legal por $16,7 \%$. Nenhum dos alunos considerou o jogo pouco legal.

Entretanto, não podemos afirmar que o sucesso do experimento coube exclusivamente ao jogo, levando-se em consideração que a escola em questão não dispõe de laboratório de informática ativo no momento, o simples fato de executar uma tarefa no computador, e em ambiente diferente da sala de aula regular, pode ter sido o suficiente para quebrar a rotina e conduzir os alunos a reagirem positivamente ao teste. 
VIII Congresso Brasileiro de Informática na Educação (CBIE 2019)

Anais do XXV Workshop de Informática na Escola (WIE 2019)

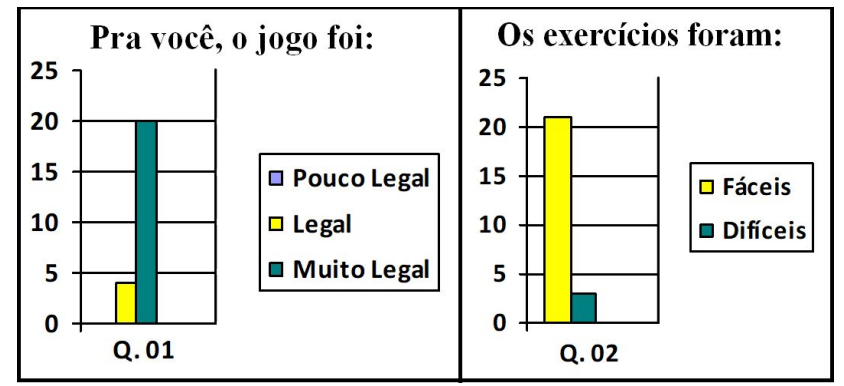

Figura 7. Gráficos com resultados das questões 1 e 2 do questionário.

Outra pergunta que revelou resultados positivos quanto à satisfação dos usuários foi se gostariam de jogar outra vez, pergunta à qual apenas um dos alunos respondeu que não. Os gráficos com os resultados das demais perguntas feitas aos usuários são apresentados abaixo na Figura 8.
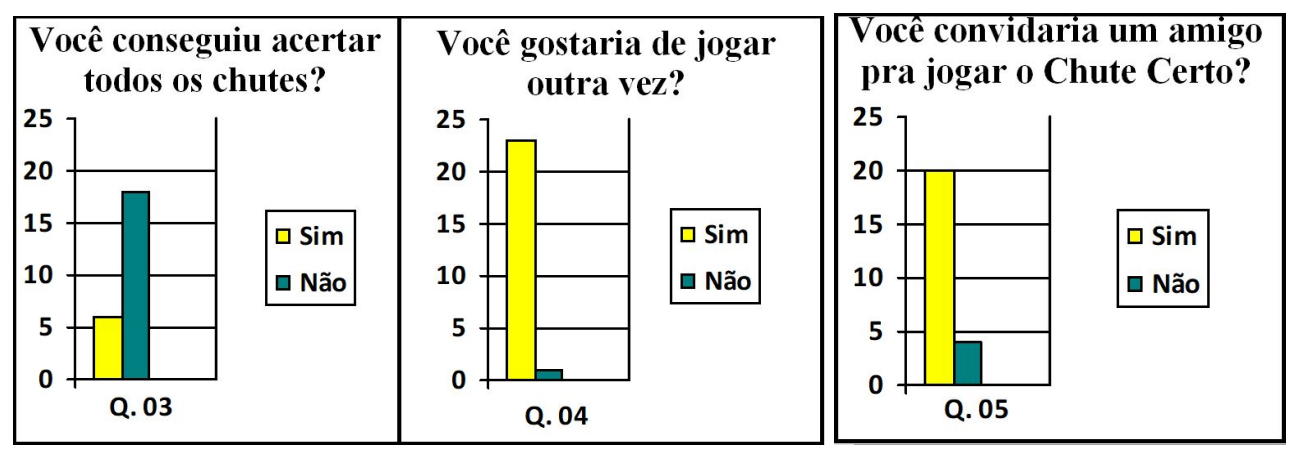

Figura 8. Gráfico com resultados das questões 3,4 e 5 do questionário.

\section{Resultados e Discussões}

O jogo Chute Certo ainda é um protótipo e nossa equipe entende que, a cada nova alteração e melhoria que ele receber, são necessários novos momentos de observação com os usuários para consolidarmos as mudanças e validarmos as habilidades que nos propomos melhorar a partir de sua prática.

Através de sua aplicação inicial, pudemos observar quais as palavras de maior dificuldade dos alunos e, com isso, melhorar as atividades de letramento desenvolvidas em sala de aula, a fim de solucionar essas dificuldades.

De modo geral, nessa fase inicial desenvolvida, foi possível avaliar algumas variáveis de usabilidade, tais como: satisfação do usuário, facilidade do uso em geral e intuitividade da interface, nível de jogabilidade e aquisição das habilidade de leitura e escrita propostas pela prática dos exercícios.

Os resultados do teste demonstram que o nível de satisfação dos usuários foi alto, embora não tenhamos como afirmar se o sucesso do experimento se deu apenas pelo jogo, já que, como falamos anteriormente, a situação de quebra de rotina é um forte motivador para os alunos. Percebemos isso tanto pelos comentários e comportamento dos alunos em sala, quanto pelo feedback da professora, que relatou o quanto os alunos ficaram satisfeitos em participar do teste, perguntando quando haveria outro momento e pedindo para participar novamente. 
Em relação à facilidade do uso em geral e intuitividade da interface, observamos que alguns alunos acabaram repetindo uma das fases já jogadas por não haver, no menu principal, uma sinalização de que aquela etapa já havia sido concluída. O botão de retorno ao menu principal, que só era ativado se clicado bem na área central, também dificultou um pouco a autonomia dos usuários com o jogo, já que foi necessária intervenção do aplicador alertando para esse detalhe sempre que essa tela aparecia.

O nível de jogabilidade foi considerado dentro do planejado para o nível dos usuários padrão. O jogo é proposto para crianças de 5 a 8 anos de idade, em fase de alfabetização. Dos 24 alunos que participaram do teste, apenas 3 consideraram os exercícios difíceis, apesar de somente 06 terem acertado todos os chutes.

Observamos que, caso o usuário ainda não seja alfabético, alguns exercícios do jogo podem parecer difíceis. Em caso de usuários alfabéticos, o nível das tarefas pode ser elevado a partir da inserção de mais bolas nas opções de resposta e da retirada da figura ilustrativa para, dessa forma, forçar mais a habilidade de leitura por parte do jogador.

Já em relação às melhorias na leitura e escrita não foi possível mensurar resultados apenas com a etapa de testes. Percebemos que seria necessária a aplicação de alguma tarefa de leitura e escrita antes e após a aplicação do jogo para a verificação da aquisição de novas habilidades.

Entretanto, é inegável a experiência de prática de leitura e observação da ortografia de cada palavra, visto que, ao repetir os exercícios não acertados, o usuário tem a chance de refazer sua escolha, memorizando a opção correta para cada palavra.

Ademais, com a prática foi possível também identificar quais palavras os alunos tinham mais dificuldade em acertar, permitindo ao professor, posteriormente, dar foco em sala à atividades com palavras do nível de maior dificuldade apresentado pelos alunos.

\section{Considerações Finais e Trabalhos Futuros}

Chute Certo é um jogo pensado para auxiliar, de forma lúdica, o processo de alfabetização de crianças de 5 a 8 anos de idade e que mostrou resultados positivos no cumprimento de sua proposta.

O jogo favorece o treino de habilidades motoras e cognitivas ao mesmo tempo que estimula e favorece o ato de brincar. Os usuários participantes da aplicação do jogo precisaram praticar especialmente a habilidade de leitura enquanto eram desafiados a acertar o máximo de gols, demonstrando que é possível treinar as aptidões inerentes ao processo de alfabetização sem, necessariamente, dizer aos alunos que aquele é o momento de estudar.

A etapa de testes em uma escola da rede pública, na qual diversos alunos encontram-se em situação de vulnerabilidade social, foi relevante tanto para esta pesquisa quanto para os membros da equipe escolar. A situação de quebra de rotina animou alunos e professores com a possibilidade de poderem contar com o apoio de um novo recurso para o alcance dos objetivos pedagógicos da série e/ou ciclo. 
VIII Congresso Brasileiro de Informática na Educação (CBIE 2019)

Anais do XXV Workshop de Informática na Escola (WIE 2019)

Como trabalhos futuros, já foram projetadas melhorias para o jogo. A primeira, e principal, é o aumento de palavras em cada nível, bem como o aumento no número de níveis disponíveis.

Outra alteração é a criação de um banco de palavras, em que os vocábulos fiquem divididos por categoria ou campo lexical. Dessa forma, o usuário poderá escolher entre dois modos de jogo: o modo aleatório, em que as palavras vão surgindo na tela sem, necessariamente, manter relação umas com as outras; E o modo personalizado, que dá ao usuário a possibilidade de escolha dos termos a partir das categorias disponíveis no banco de palavras, garantindo assim, que os treinos sejam feitos de forma contextualizada com o que estiver sendo estudado pela turma e a prática do jogo seja ainda mais significativa.

Por fim, implementar-se-á uma funcionalidade especial para o professor, apresentando dados sobre cada aluno, com o número de acertos individual, as palavras erradas, o tempo gasto para decidir a sílaba, e mais informações consideradas de extrema importância para identificar o nível de letramento do aluno. Essa funcionalidade auxiliará o professor a elaborar atividades mais focadas nas dificuldades dos alunos.

\section{Referências}

Brasil, Lei no 13.005. (2014). Aprova o Plano Nacional da Educação - PNE e dá outras providências, http://www.planalto.gov.br/CCIVIL_03/_Ato2011-2014/2014/Lei/L13005.htm, Junho.

Ministério da Educação. Avaliação Nacional da Alfabetização - Edição 2016, http://portal.mec.gov.br/index.php?option=com_docman\&view=download\&alias=75 181-resultados-ana-2016-pdf\&category_slug=outubro-2017-pdf\&Itemid=30192, Junho.

Nogueira, D., Coscarelli, C., Chiamowicz, L. (2010). "Papa Letras: Um jogo de auxílio à alfabetização infantil". Em Anais do IX Simpósio Brasileiro de Jogos e Entretenimento Digital (SBGames).

Coscarelli, C. (2013). "Projeto Aladim: Jogos digitais e novas interfaces para alfabetização". Em Revista Triângulo, v. 6, n.2, p. 04-15, 2013.

Pinheiro, R. C., Cavalcante, G. R. M., Amorim, N. O. (2018). "Jogos digitais para alfabetização: avaliando e reconfigurando o jogo Batalha Naval". Em Revista Domínio de Linguagem, v.12, n.1, p. 653-680, 2018.

Beck, K., Beedle, M., van Bennekum, A. et al. (2001) "Manifesto for Agile Software Development", http://agilemanifesto.org/, Julho.

Leão, M. A. (2015). "O uso de jogos como mediadores da alfabetização/letramento em sala de apoio das séries iniciais". Em Estudos Linguísticos, São Paulo, 44 (2): p. 647-656.

LEMLE, M. (2006). "Guia teórico do alfabetizador". 16. ed. São Paulo: Ática, 2006. Série: Princípios. 